\title{
Epigenetic modulation of AR gene expression in prostate cancer DU145 cells with the combination of sodium butyrate and 5'-Aza-2'-deoxycytidine
}

\author{
BARBORA FIALOVA ${ }^{1}$, PETRA LUZNA ${ }^{1}$, JAN GURSKY ${ }^{2}$, KATERINA LANGOVA ${ }^{2}$, \\ ZDENEK KOLAR $^{1}$ and KATERINA SMESNY TRTKOVA ${ }^{1,2}$
}

\author{
${ }^{1}$ Department of Clinical and Molecular Pathology, Faculty of Medicine and Dentistry, Palacky University Olomouc; \\ ${ }^{2}$ Institute of Molecular and Translational Medicine, Palacky University Olomouc \\ and University Hospital, Olomouc, Czech Republic
}

Received February 11, 2016; Accepted June 24, 2016

DOI: 10.3892/or.2016.5000

\begin{abstract}
The androgen receptor (AR) plays an essential role in the development and progression of prostate cancer. Castration-resistant prostate cancer (CRPC) is a consequence of androgen deprivation therapy. Unchecked CRPC followed by metastasis is lethal. Some CRPCs show decreased $A R$ gene expression due to epigenetic mechanisms such as DNA methylation and histone deacetylation. The aim of this study was to epigenetically modulate the methylated state of the $\mathrm{AR}$ gene leading to targeted demethylation and AR gene expression in androgen-independent human prostate cancer DU145 cell line, representing the CRPC model with very low or undetectable AR levels. The cell treatment was based on single and combined applications of two epigenetic inhibitors, sodium butyrate $(\mathrm{NaB})$ as histone deacetylases inhibitor and 5'-Aza-2'-deoxycytidine (Aza-dC) as DNA methyltransferases inhibitor. We found that the Aza-dC in combination with $\mathrm{NaB}$ may help reduce the toxicity of higher $\mathrm{NaB}$ concentrations in
\end{abstract}

Correspondence to: Dr Katerina Smesny Trtkova, Department of Clinical and Molecular Pathology, Faculty of Medicine and Dentistry, Palacky University Olomouc, Hnevotinska 3, 77515 Olomouc, Czech Republic

E-mail: katerina.smesny@upol.cz

Abbreviations: AR, androgen receptor; Aza-dC, 5'-Aza-2'-deoxycytidine; BCLT, bicalutamide; BPE, bovine pituitary extract; $\mathrm{CaP}$, prostate cancer; ChIP, chromatin immunoprecipitation; CRPC, castration-resistant prostate cancer; DMSO, dimethylsulfoxide; DNMTs, DNA methyltransferases; D-PBS, Dulbecco's phosphatebuffered saline; FBS, fetal bovine serum; HDACs, histone deacetylases; MBD2, methyl-CpG binding domain protein 2; MTT, 3-(4,5-dimethylthiazol-2-yl)-2,5-diphenyltetrazolium bromide; $\mathrm{NaB}$, sodium butyrate; PBS, phosphate-buffered saline; PI, propidium iodide; PI3K/AKT, phosphatidylinositol-3-kinase/protein kinase B; PSA, prostate specific antigen; TRAMP, transgenic adenocarcinoma mouse prostate

Key words: prostate cancer, androgen receptor, epigenetics cancer cells. In normal RWPE-1 cells and even stronger in cancer DU145 cells, the combined treatment induced both $A R$ gene expression on the mRNA level and increased histone $\mathrm{H} 4$ acetylation in AR gene promoter. Also activation and maintenance of G2/M cell cycle arrest and better survival in normal RWPE-1 cells compared to cancer DU145 cells were observed after the treatments. These results imply the selective toxicity effect of both inhibitors used and their potentially more effective combined use in the epigenetic therapy of prostate cancer patients.

\section{Introduction}

Castration-resistant prostate cancer (CRPC) develops over time as a consequence of androgen deprivation therapy $(1,2)$ and this is enhanced by epithelial-mesenchymal transition and cancer stem cells (reviewed in ref. 3). Unchecked CRPC followed by metastasis is lethal (4) due to limited options for treatment. The mechanisms by which prostate cancer cells acquire castration resistance are numerous and include activation of alternative pathways with dominant PI3K/AKT signaling, androgen receptor (AR) gene mutations leading to promiscuous activations $(5,6)$, and recently identified AR splice variants among other factors $(7,8)$.

DNA methylation is one of the most intensely studied epigenetic modifications that appears to be a decisive event in the initiation and development of advanced $\mathrm{CaP}$ with the process of DNA hypermethylation preceding to global hypomethylation $(9,10)$. Friedlander et al (4) compared CRPC and benign tissue methylation profiles with the finding of hypermethylated genomic DNA in CRPC patients. Moreover, in these patients, DNA methylations at individual $\mathrm{CpG}$ loci both within and outside $\mathrm{CpG}$ islands were found much more frequently than common copy number changes. Methylated DNA could thus be a treatment target for delaying the progression of the castration-resistant disease using PI3K/AKT inhibitors and hypomethylating agents (4).

AR plays an essential role in advanced CaP (11). Some CRPC expresses the $A R$ gene in autocrine pathways and remains dependent on AR while other cancer cells show decreased $A R$ 
gene expression attributed to impaired AR protein stability, $\mathrm{X}$ chromosome loss or DNA methylation silencing and are independent of AR (7). Tian et al (12) showed a link between $A R$ gene methylation and prostate cancer progression. These authors found that $A R$ gene methylation in promoter regions was likely related to prostate stem/progenitor cell stemness and differentiation. Low expression of the AR in prostate cancer stem cells and LNCaP progenitor/stem cells were found to be due to high DNA methyltransferase 1/3 level and MBD2 promoter binding. Moreover, treatment of prostate cancer cells with $5 \mu \mathrm{M}$ 5'-Aza-2'-deoxycytidine (Aza-dC) resulted in the inhibition of self-renewal/growth of prostate stem/progenitor cells in vitro, reduced prostate tumorigenicity in vivo followed by induction of the $A R$ gene and functional protein expression in a time-dependent manner following 6 days incubation with $5 \mu \mathrm{M}$ Aza-dC.

The hypothesis that epigenetically induced AR expression in CRPC with AR methylated pattern might revert some deleterious pathways and to some extent reduce the aggressiveness of the cancer cells, is supported by several studies. McCabe et al (13) for example found that Aza-dC inhibited aberrant de novo DNA methylation in the TRAMP mouse model and prevented $\mathrm{CaP}$ development during the drug administration. Zorn et al (14) reported the delayed emergence of androgen-independent $\mathrm{CaP}$ in castrated TRAMP mice after Aza-dC treatment. Moreover, combined treatment by castration and Aza-dC administration showed statistically significant longer survival than single treatment. In a preclinical study, Gravina et al (15) used 5-azacytidine for reactivation of AR gene expression, silenced by DNA methylation in the PC3 cell line. This led to resensitisation to bicalutamide (BCLT) responsiveness and subsequent apoptosis. In detail, 5-azacytidine treatment increased the effect of BCLT therapy in AR-expressing and AR-deficient prostate cancer, both in vitro and in vivo. Co-treatment with both agents led to synergistic/additive effects in nude male mice xenografted with 22rv1 and PC3 cells (AR-expressing or AR-deficient cell lines, respectively) followed by significantly reduced tumor mass and delayed cancer progression. In the co-treated cell lines (22rv1 and PC3), increased cell cycle and apoptosis proteins expression were observed.

This study describes the epigenetic consequences of the combined treatment of two inhibitors, sodium butyrate $(\mathrm{NaB})$ as a histone deacetylase (HDAC) inhibitor and 5'-Aza-2'deoxycytidine (Aza-dC) as a DNA methyltransferase (DNMT) inhibitor, in both cancer and normal prostate cells. DNA methyltransferases (DNMTs) and histone deacetylases (HDACs) are co-regulators of the AR and could imply potential targets for affecting androgen receptor function and stability. These are now an option in epigenetic treatment (16) with the aim of overcoming the mechanism of hormonal resistance and in its consequences, of target therapy to regulation of the AR without therapy based on hormone treatment. Our previous results (17) showed demethylation of specific $\mathrm{CpG}$ sites in the AR gene in the DU145 prostate cancer cell line following co-treatment with Aza-dC and $\mathrm{NaB}$. The focus of this study was the methylated $\mathrm{AR}$ gene with subsequent epigenetic modulation leading to targeted histone acetylation and AR gene re-expression. Our results imply that the epigenetic drugs used, depending on the concentration, affected the acetylation level of histones $\mathrm{H} 3$ and $\mathrm{H} 4$ in a vicinity of the AR gene promoter. In addition, the used epigenetic agents induced activation and maintaining of G2/M cell cycle arrest in RWPE-1 cells. Better survival in normal RWPE-1 cells compared to cancer DU145 cells implies the selective toxic effects of the used inhibitors.

\section{Materials and methods}

Cell culture, treatment conditions and viability assay. The androgen-independent human prostate cancer cell line DU145 was purchased from ATCC (Rockville, MD, USA), maintained in DMEM (Gibco) supplemented with $10 \%$ fetal bovine serum (FBS), $0.01 \%$ antibiotics, $2 \mathrm{mM}$ L-glutamine. Non-tumorigenic, immortalized human prostate cell line RWPE-1 was kindly provided by the Department of Experimental Biology, Masaryk University (Brno, Czech Republic). The normal cell line RWPE-1 was cultivated in keratinocyte-SFM medium (kit) with L-glutamine, human recombinant epidermal growth factor (EGF) and bovine pituitary extract (BPE) (Gibco) supplemented with a final $0.01 \%$ concentration combination of penicillin and streptomycin, $0.01 \%$ concentration of amfomycin and $0.005 \%$ concentration of gentamycin. All cells were maintained at $37^{\circ} \mathrm{C}$ and $5 \% \mathrm{CO}_{2}$ atmosphere. Both cell lines were treated with $\mathrm{NaB}$ (Sigma-Aldrich), Aza-dC (Sigma-Aldrich) and their combinations for 2 and 6 days when medium and agents were changed after 2 days. Cell viability assays of cells were performed using 3-(4,5-dimethylthiazol-2-yl)-2,5-diphenyltetrazolium bromide agent (MTT) as described (17). The cancer cell line DU145 was seeded on 96-well plates at 4,500 cells per well and RWPE-1 cells at 6,000 cells per well and increased to 40-50\% confluent prior to the first treatment. The cell culture medium with inhibitors was changed after 2 days for 6-day treatments. All treatments were performed in triplicate. The percentage of viable cells was calculated as follows: average absorbance of treated cells/ average absorbance of control cells x 100 .

$m R N A$ analysis using $R T-q P C R$. The cells were seeded in $100-\mathrm{mm}$ dishes $\left(1 \times 10^{6}\right.$ cells for RWPE- 1 and $7 \times 10^{5}$ for DU145 cells) and treated with $5 \mu \mathrm{M}$ Aza-dC, $5 \mathrm{mM} \mathrm{NaB}$ and their combinations $(0.5 \mu \mathrm{M}$ Aza-dC $+1 \mathrm{mM} \mathrm{NaB}, 0.5 \mu \mathrm{M}$ Aza- $\mathrm{dC}+$ $5 \mathrm{mMNaB}$ and $5 \mu \mathrm{M}$ Aza-dC $+5 \mathrm{mM} \mathrm{NaB}$ ) for 2 and 6 days when medium and agents were exchanged after 2 days in prolonged 6-days culture. Total RNA from both cell lines was isolated with High Pure RNA Isolation kit (Roche) and 1,000-1,500 ng of total RNA was converted to cDNA using Transcriptor First Strand cDNA synthesis kit (Roche), in both cases according to the manufacturer's instructions. For following quantitative realtime PCR analyses, the total amount of $100 \mathrm{ng}$ of cDNA from each sample was amplified using Taq-Man probes labelled with hexafluorescein and Thermo-Start DNA Polymerase (AB gene) using the real-time PCR analyser Rotor-Gene RG-3000 (Corbett Research). Primers and probe sequences for AR, PSA (prostate specific antigen) and GAPDH genes are summarized in Table I. The experiments were performed in triplicate with a similar pattern of results.

Chromatin immunoprecipitation coupled with quantitative $P C R(C h I P-q P C R)$. ChIP was performed on both cell lines as described (17) with the following modifications: briefly, the cells were seeded in $100-\mathrm{mm}$ dishes $\left(1 \times 10^{6}\right.$ cells for RWPE-1) 
Table I. Primer sequences and probes used for mRNA and ChIP-qPCR assays.

\begin{tabular}{|c|c|c|c|c|}
\hline GOI & Forward $\left(5^{\prime}-3^{\prime}\right)$ & Reverse $\left(5^{\prime}-3^{\prime}\right)$ & Probe $\left(5^{\prime}-3^{\prime}\right)$ & $\begin{array}{l}\text { Product } \\
\text { (bp) }\end{array}$ \\
\hline AR & ATCCCAGTCCCACTTGTGTC & GGTCTTCTGGGGTGGAAAGT & AAGCGAAATGGGCCCTGGA & 137 \\
\hline PSA & CGGAGAGCTGTGTCACCAT & CACAATCCGAGACAGGATGA & CGTGGATTGGTGCTGCACCC & 95 \\
\hline GAPDH & GAAGATGGTGGGGATTTC & GAAGGTGAAGGTCGGAGT & CAAGCTTCCCGTTCTCAGCC & 226 \\
\hline AR & CAGGAGCTATTCAGGAAGCAG & GGCTTTGGAGAAACAAGTGC & СTCCTGCC & 93 \\
\hline
\end{tabular}

(ChIP)

GOI-gene of interest.

and in $150-\mathrm{mm}$ dishes $\left(1.9 \times 10^{6}\right.$ cells for DU145). After a formaldehyde cross-linking terminated by glycine, RWPE-1 cells were washed with Dulbecco's phosphate-buffered saline (D-PBS) instead of standard PBS used for DU145 line. Cells were immunoprecipitated with $2 \mu \mathrm{g}$ anti-acetyl histone $\mathrm{H} 3$ rabbit polyclonal antibody (cat. 06-599), and anti-acetyl histone $\mathrm{H} 4$ rabbit polyclonal antibody (cat. 06-866, both from Millipore), and normal mouse IgG polyclonal antibody (cat. 12-371, Millipore). For input, $100 \mu \mathrm{g}$ of each chromatin lysates and $1 \mu \mathrm{l}$ of proteinase $\mathrm{K}(100 \mu \mathrm{g} / \mathrm{ml})$ were added to each tube, incubation at $55^{\circ} \mathrm{C}$ for $3 \mathrm{~h}$ with gentle agitation was performed followed by DNA purification with QIAquick $^{\circledR}$ PCR Purification kit (Qiagen). Quantitative PCR analyses were performed on LightCycler 480 (Roche) with probe no 51 (Universal Probe Library cat. no. 04688481001) using ProbeFinder assay design software and primers amplifying AR gene promoter region (Table I). DNA from each input sample was diluted 10x and primer efficiency was tested. All experiments were repeated three times independently and all measurements were performed in triplicate.

Cell cycle analysis. Briefly, the cell lines were seeded in 6-well plates $\left(2.2 \times 10^{5}\right.$ cells for RWPE- 1 and $1.5 \times 10^{5}$ cells for DU145) and treated with the same inhibitors and their combinations for 2 and 6 days as described above. Cells were harvested at indicated times after treatment, also detached cells were collected. Samples were fixed in cold $70 \%$ ethanol. After treatment with RnaseA, samples were stained with propidium iodide (PI). Cellular DNA content was analyzed using flow cytometry (BD FACSVerse, BD, USA) and collected data were processed using BD FACSuite (BD). At least 10,000 cells per sample were analyzed.

Statistical analysis. Multifactoral analysis of variance (ANOVA) with post-hoc two-tailed Dunnett's t-test and Bonferroni multiple comparison test were used for cell viability assays and quantitative experiments. All statistical analyses were performed with the SPSS software version 15 (SPSS, Inc. Chicago, Il, USA) and the significance level was set at $\mathrm{p}<0.05$ (two-tailed).

\section{Results}

Aza-dC decreases cytotoxicity of NaB in prostate cancer cells. Cell viability was analysed using MTT assay to compare cell cytotoxicity after treatment with one of the inhibitors used or inhibitor combinations. In DU145 cells treated with $\mathrm{NaB}$ or Aza-dC, or combinations of different concentrations of Aza-dC with $\mathrm{NaB}$ (Fig. 1), the cell viability was significantly lower following all treatments after 6 days than in 2-day experiments ( $\mathrm{p} \leq 0.0004$ for Aza-dC treatment, $\mathrm{p} \leq 0.0001$ for co-treatment, Fig. 1B and C, respectively). The 6-day treatment with $\mathrm{NaB}$ (Fig. 1A) showed significantly lower cell viability, ranging from $2.5 \mathrm{mM}$ concentration $(\mathrm{p}=0.002$ and $\mathrm{p}<0.0001$ for 4 and $5 \mathrm{mM} \mathrm{NaB}$ ), and higher cell viability after treatment with 0.25 and $0.5 \mathrm{mM}$ concentrations $(\mathrm{p}=0.0001$ for both treatments) compared with the same conditions in the 2-day experiment. The images of prostate cancer cells DU145 (Fig. 2) demonstrate changes in cell viability after 2 and 6 days of cultivation with $5 \mathrm{mM} \mathrm{NaB}$ and with $0.5 \mu \mathrm{M}$ Aza-dC + $5 \mathrm{mM} \mathrm{NaB}$ co-treatment compare with DMSO. Changes of cell viability in DU145 cells are comparable with the results of MTT assay (Fig. 1A and C) and suggest a lower cytotoxicity of $0.5 \mu \mathrm{M}$ Aza-dC $+5 \mathrm{mM} \mathrm{NaB}$ combination used than $5 \mathrm{mM}$ $\mathrm{NaB}$ treatment alone.

In normal RWPE-1 cells, the 6-day incubation led to significantly lower cell viability on treatment with $\mathrm{NaB}$ alone $(\mathrm{p}<0.0001$; Fig. 1D) and $\mathrm{NaB}$ co-treatment with Aza-dC ( $\mathrm{p} \leq 0.008$; Fig. $1 \mathrm{~F}$ ) in all concentrations compared to 2 days. The highest 4 and $5 \mu \mathrm{M}$ Aza- $\mathrm{dC}$ concentrations caused higher toxicity after 6 days than the 2-day experiment (Fig. 1E, $\mathrm{p}=0.028$ and 0.007 , respectively). In contrast, no differences in cell viability were observed on treatment with $0.5-2 \mu \mathrm{M}$ Aza-dC concentrations between 2- and 6-day experiments.

A combination of the Aza-dC and NaB treatment induces $A R$ gene re-expression in prostate cancer cells. When designing the RT-qPCR, we followed results from the MTT assay (Fig. 1) and from our previous bisulfite sequencing results in DU145 cells (17), where the most effective DNA demethylation effect was after 2-day treatment with $0.5 \mu \mathrm{M}$ Aza-dC $+5 \mathrm{mM}$ $\mathrm{NaB}$ in the AR gene. Here in DU145 cells (Fig. 3A and B), co-treatment with the combination of $0.5 \mu \mathrm{M}$ Aza-dC $+5 \mathrm{mM}$ $\mathrm{NaB}$ led to most significantly higher AR gene re-expression after both 2- and 6-day incubations. The $5 \mu \mathrm{M}$ Aza-dC cell treatment had no effect on AR gene re-expression after 2 days (Ct undetectable; Fig. 3A) as was further confirmed by mRNA analysis, although a weak signal detection was observed after the 6-day exposure (Fig. 3B). As the $0.5 \mu \mathrm{M}$ Aza-dC $+5 \mathrm{mM}$ $\mathrm{NaB}$ co-treatment, the $5 \mathrm{mM} \mathrm{NaB}$ treatment and $5 \mu \mathrm{M}$ Aza-dC 

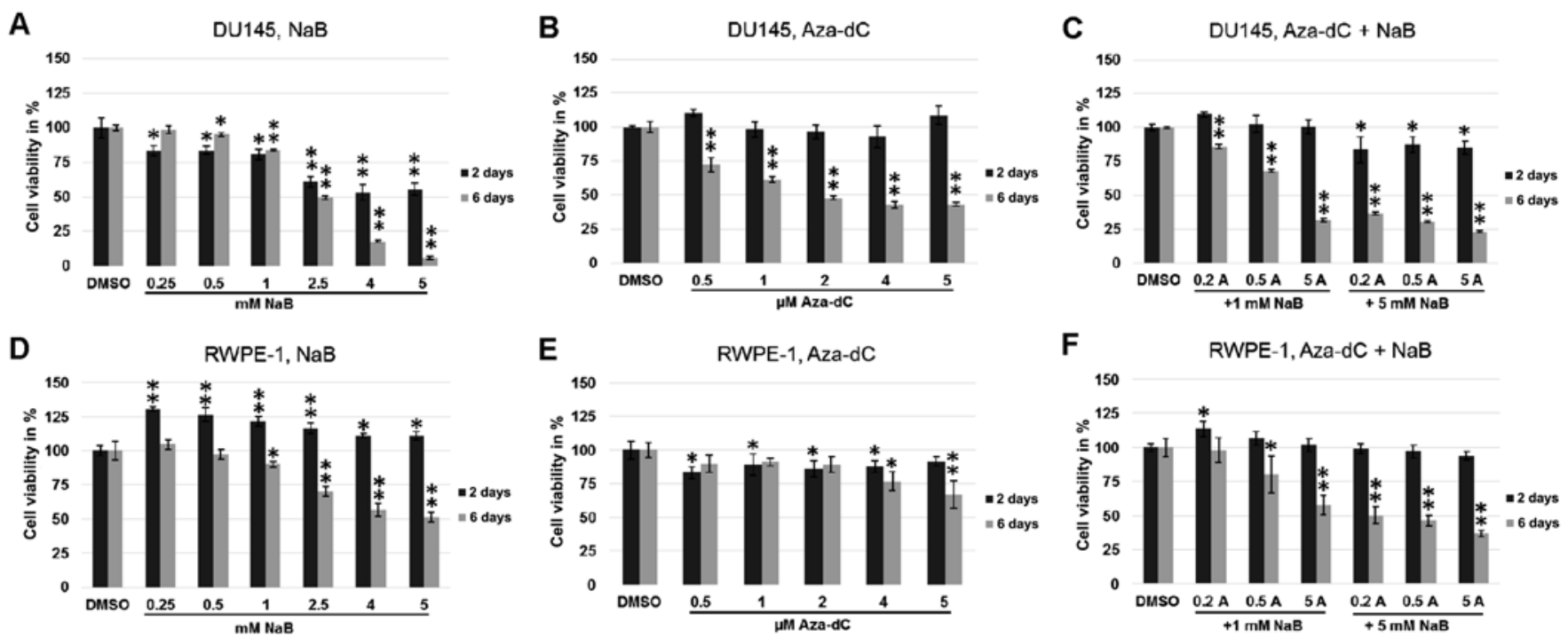

Figure 1. DU145 (A-C) and RWPE-1 (D-F) cell viabilities after 2 and 6 days treated with NaB, Aza-dC and Aza-dC + NaB combinations. The data at each treatment point represent the means \pm SE of triplicate wells. Asterisks show statistically significant differences between treatment and control DMSO. ${ }^{*}$ p $<0.05$ value, ${ }^{* *} \mathrm{p}<0.0001$.
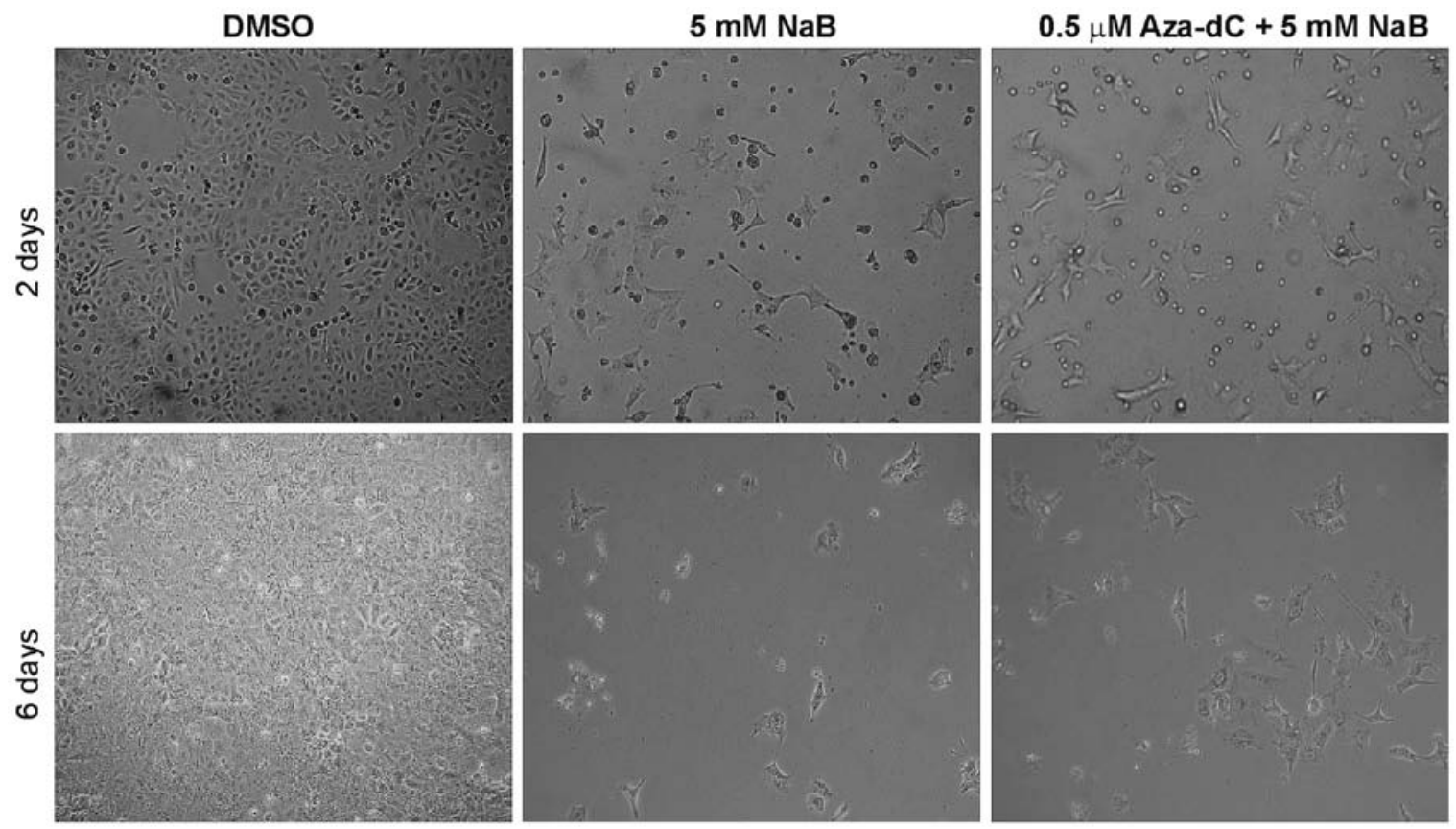

Figure 2. Visual appearance of DU145 cell line after treatment with $5 \mathrm{mM} \mathrm{NaB}$ and the combination $0.5 \mu \mathrm{M}$ Aza-dC $+5 \mathrm{mM} \mathrm{NaB}$ after 2 and 6 days.

$+5 \mathrm{mM} \mathrm{NaB}$ combination were also effective in inducing significant AR mRNA re-expression.

In normal RWPE-1 cells (Fig. 3C and D), we found that AR gene expression was enhanced by all treatments with the highest effect after $5 \mathrm{mM} \mathrm{NaB}$ treatment, where only the 2-day experiment showed statistically significant differences between $5 \mathrm{mM} \mathrm{NaB}, 0.5 \mu \mathrm{M}$ Aza-dC $+5 \mathrm{mM} \mathrm{NaB}$ and $5 \mu \mathrm{M}$ Aza-dC $+5 \mathrm{mM} \mathrm{NaB}$ co-treatments.

Comparing the results from the mRNA analysis in both cell lines used (Fig. 3), a tendency to overall decrease in AR mRNA expression after 6-day treatment was observed. The treatments with $5 \mu \mathrm{M}$ Aza-dC and $0.5 \mu \mathrm{M}$ Aza-dC $+1 \mathrm{mM}$
$\mathrm{NaB}$ in DU145 and RWPE-1 cells were weak or ineffective in re-expressing the AR. However, no PSA gene expression at either time course or in either cell line was detected $(\mathrm{Ct}$ undetectable).

The NaB increases histone H4 acetylation, but not histone H3 in prostate cancer cells affected with epigenetic modulators. Since histone deacetylation is a hallmark of silent condensed chromatin, to explore whether single $\mathrm{NaB}$ or its combinations with Aza-dC could be effective in initiating the AR gene re-expression through histone re-acetylation, we used the same treatment as described for mRNA analysis followed by chro- 
A

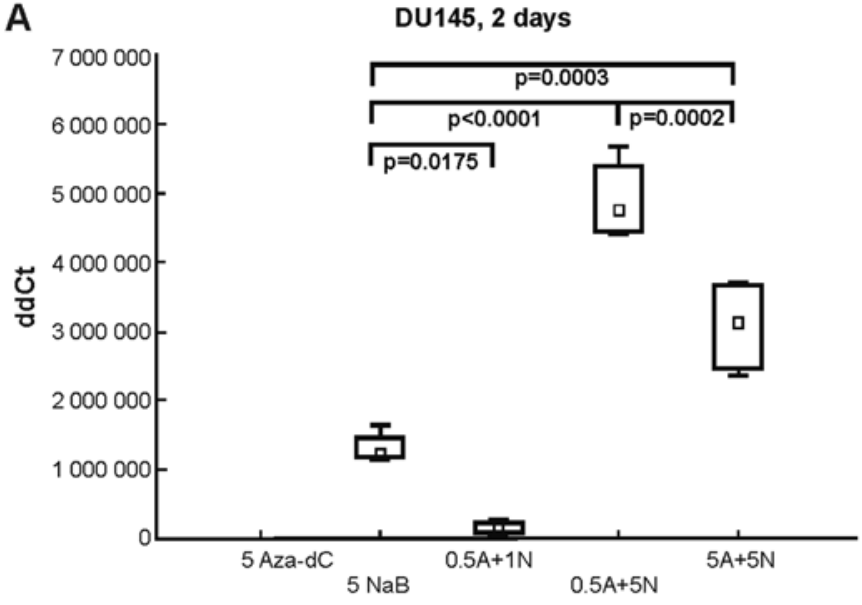

C

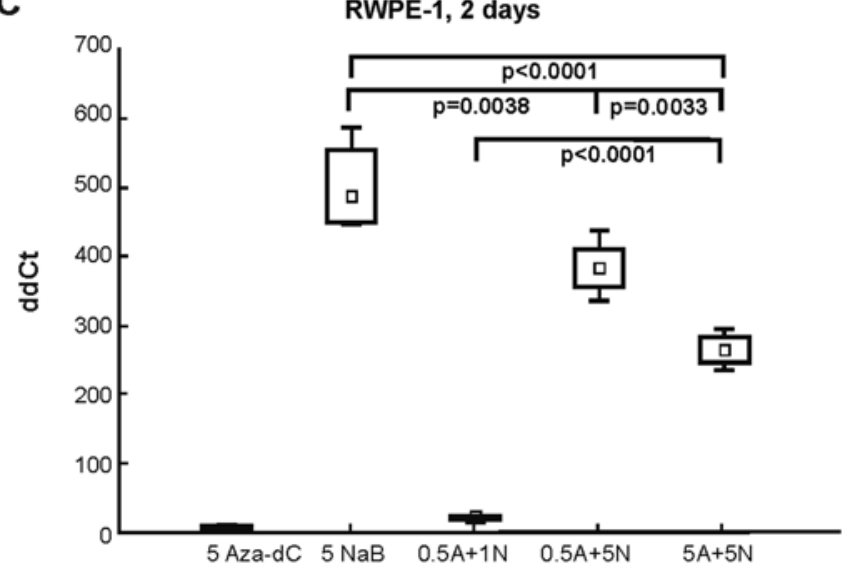

B

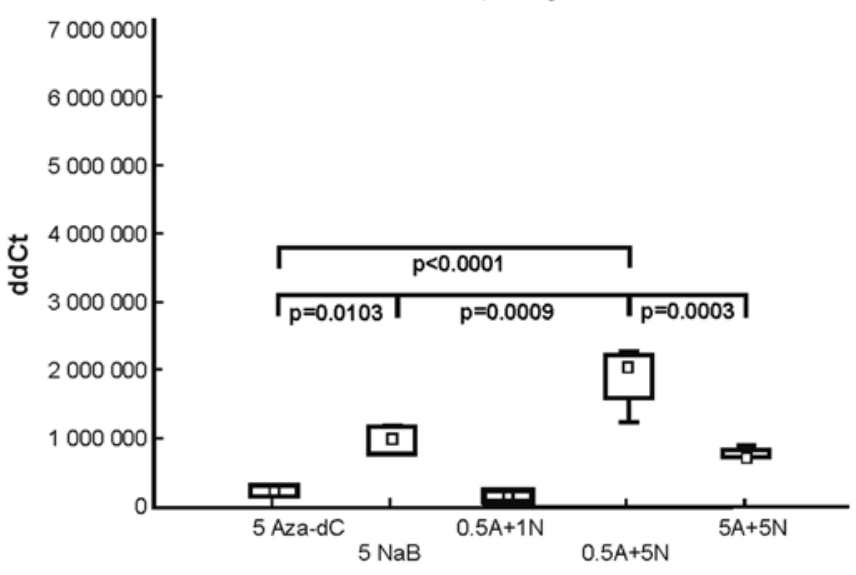

D

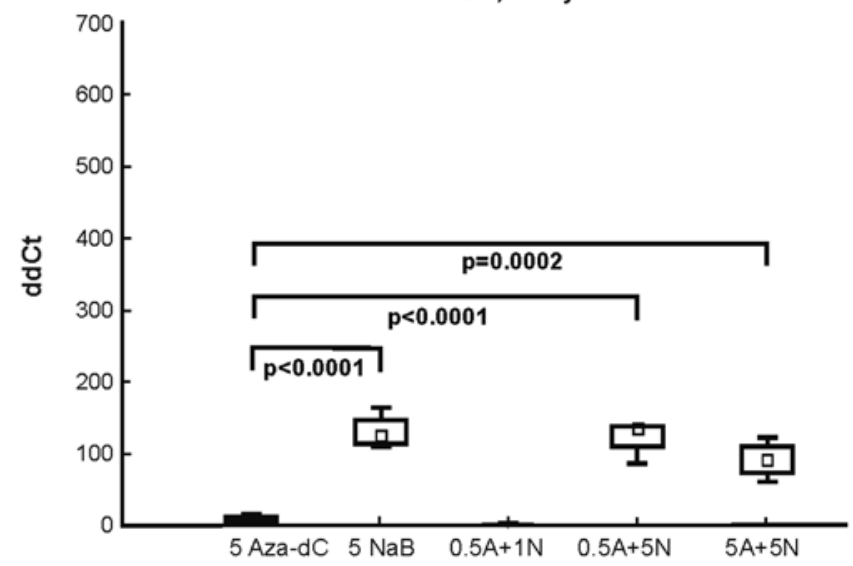

Figure 3. The AR gene expression in DU145 and RWPE-1 cells. For relative AR expression, the $2^{-\Delta A C t}$ method normalized to GAPDH was used. The statistical significance was set at $\mathrm{p}<0.05$ (two-tailed). Two day-treatment of both cell lines, DU145 (A) and RWPE-1 (C), showed relative expression of AR mRNA treated with the same regime. Six-day exposure of DU145 (B) and RWPE-1 (D) lines to the same conditions. $0.5 \mathrm{~A}+1 \mathrm{~N}, 0.5 \mu \mathrm{M}$ Aza-dC $+1 \mathrm{mM} \mathrm{NaB} ; 0.5 \mathrm{~A}+5 \mathrm{~N}, 0.5 \mu \mathrm{M}$ Aza-dC $+5 \mathrm{mM} \mathrm{NaB} ; 5 \mathrm{~A}+5 \mathrm{~N}, 5 \mu \mathrm{M}$ Aza-dC $+5 \mathrm{mM} \mathrm{NaB}$.

matin immunoprecipitation coupled with qPCR. Sonicated chromatin samples were immunoprecipitated with anti-acetyl histone H3-lysine 4, -lysine 9, -lysine 14 and -lysine 18 (H3K4, $\mathrm{H} 3 \mathrm{~K} 9, \mathrm{H} 3 \mathrm{~K} 14$ and $\mathrm{H} 3 \mathrm{~K} 18$, respectively) and anti-acetyl histone H4-lysine 5, -lysine 8, -lysine 12 and -lysine 16 (H4K5, H4K8, H4K12 and H4K16, respectively) antibodies. Normal IgG antibody served as a negative control, and sonicated chromatin samples were processed with no added antibody (NoAb sample) as a mock control (or noise control). The NoAb sample was processed as the standard sample used for IP without antibody and served as an internal control to minimize noise of the manual workflow. ChIP-qPCR results were analyzed by evaluating the signal of enrichment over noise normalized to input (18).

In DU145 cells treated for 2 days with $0.5 \mu \mathrm{M}$ Aza-dC + $1 \mathrm{mM} \mathrm{NaB}$ and the $0.5 \mu \mathrm{M} \mathrm{Aza}-\mathrm{dC}+5 \mathrm{mM} \mathrm{NaB}$ (Fig. 4A), co-treatments were significantly more effective for histone $\mathrm{H} 3$ acetylation than the DMSO control. Monitored histone $\mathrm{H} 4$ sites were acetylated following all treatments except for the $5 \mu \mathrm{M}$ Aza-dC treatment (Fig. 4A). In 6 days (Fig. 4B), the histone H3 acetylation increased after cell treatment with $5 \mathrm{mM} \mathrm{NaB}$ alone and with the $5 \mu \mathrm{M}$ Aza-dC $+5 \mathrm{mM} \mathrm{NaB}$ combination, and decreased after treatments with $5 \mu \mathrm{M}$ Aza-dC, $0.5 \mu \mathrm{M}$ Aza-dC $+1 \mathrm{mM} \mathrm{NaB}$ and $0.5 \mu \mathrm{M}$ Aza-dC $+5 \mathrm{mM} \mathrm{NaB}$ in comparison with untreated DMSO. We observed significant increase in histone $\mathrm{H} 4$ acetylation in the AR gene promoter region for all treatments, while the $5 \mu \mathrm{M}$ Aza-dC treatment was ineffective (Fig. 4B).

In the RWPE-1, after 2-day treatment (Fig. 4C), we found significant decrease in the histone $\mathrm{H} 3$ acetylation targeted to the AR gene promoter for all used treatments except for $5 \mathrm{mM} \mathrm{NaB}$. Significant upregulation of histone $\mathrm{H} 4$ acetylation was observed in cells treated with $5 \mathrm{mM} \mathrm{NaB}$ alone and with subsequent combinations of $0.5 \mu \mathrm{M}$ Aza-dC $+5 \mathrm{mM} \mathrm{NaB}$ and $5 \mu \mathrm{M}$ Aza-dC $+5 \mathrm{mM} \mathrm{NaB}$. Downregulation of histone $\mathrm{H} 4$ acetylation was observed following treatment with $0.5 \mu \mathrm{M}$ Aza-dC $+1 \mathrm{mM} \mathrm{NaB}$ combination but no significant change was detected after treatment with $5 \mu \mathrm{M}$ Aza-dC alone. After 6 days (Fig. 4D), the RWPE-1 cells showed lower levels of histone $\mathrm{H} 3$ acetylation for all used treatments except $0.5 \mu \mathrm{M}$ Aza-dC $+5 \mathrm{mM} \mathrm{NaB}$ application compare to DMSO.

Comparing histone $\mathrm{H} 3$ and $\mathrm{H} 4$ acetylations between 2- and 6-day experiments, we found a decrease in histone $\mathrm{H} 3$ acetylation in DU145 cells treated with $0.5 \mu \mathrm{M}$ Aza-dC $+1 \mathrm{mM} \mathrm{NaB}$ combination ( $\mathrm{p}=0.049$; Fig. $4 \mathrm{~A}$ and $\mathrm{B}$ ) while control DMSO treatment and subsequent applications of $5 \mu \mathrm{M}$ Aza-dC alone and $5 \mu \mathrm{M}$ Aza-dC $+5 \mathrm{mM} \mathrm{NaB}$ combination induced significant time-dependent enrichment $(\mathrm{p}=0.001,0.039$ and 
A

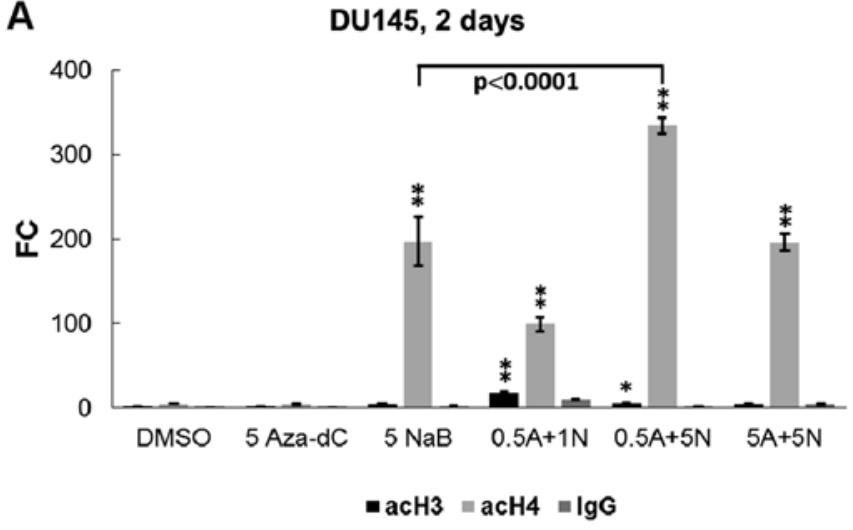

C

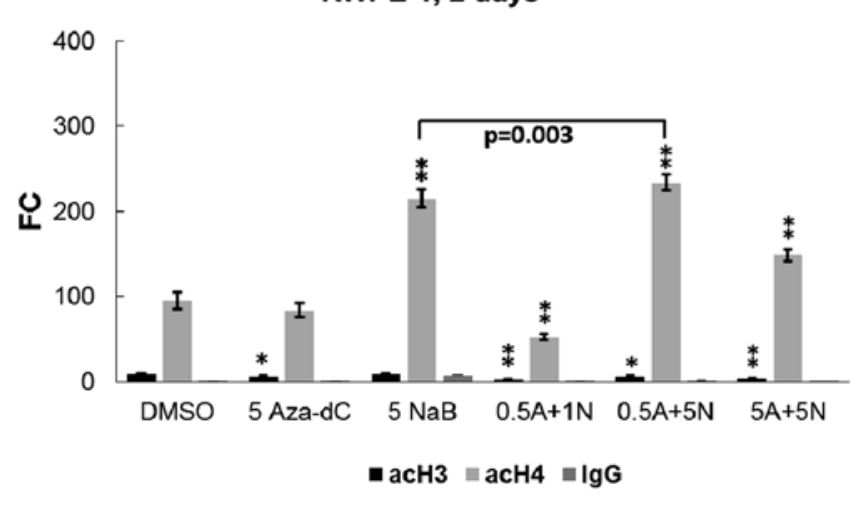

B

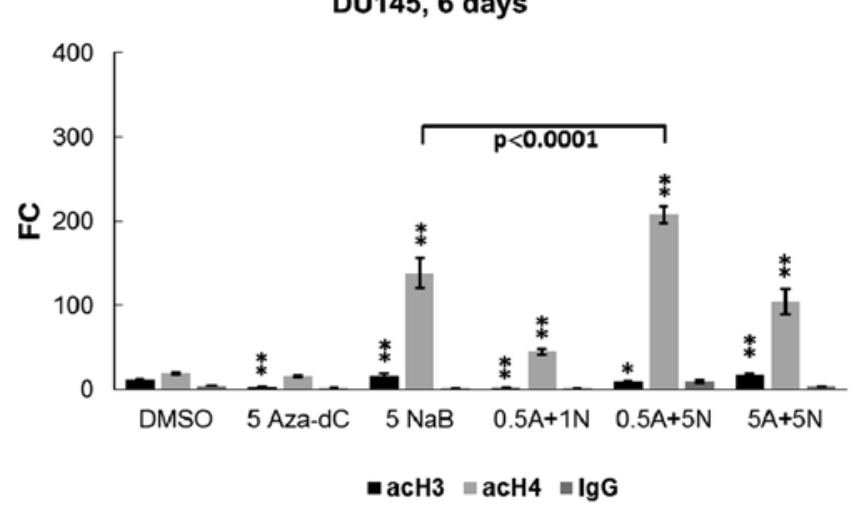

D

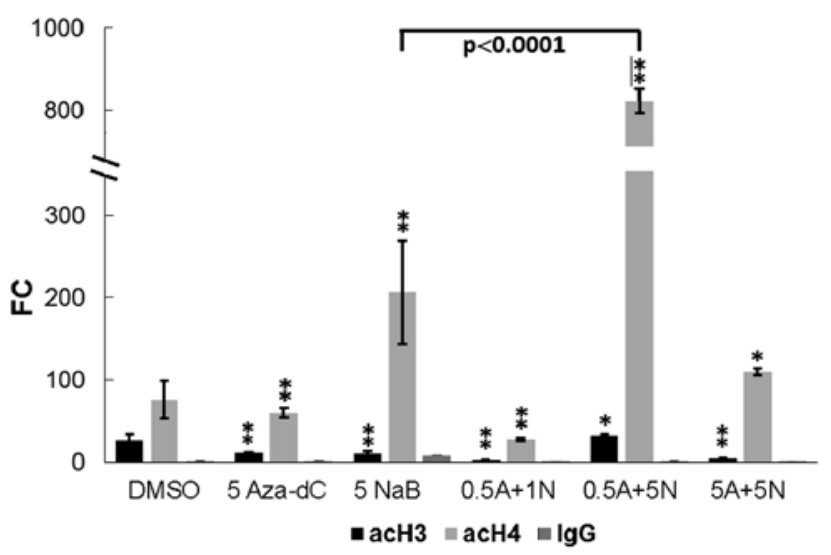

Figure 4. Chromatin immunoprecipitation paired with qPCR. Untreated cells (DMSO) and cells treated with $5 \mu \mathrm{M} \mathrm{Aza-dC} \mathrm{(5} \mathrm{Aza-dC),} 5 \mathrm{mM} \mathrm{NaB}(5 \mathrm{NaB})$ and their combinations $0.5 \mu \mathrm{M}$ Aza-dC $+1 \mathrm{mM} \mathrm{NaB}(0.5 \mathrm{~A}+1 \mathrm{~N}), 0.5 \mu \mathrm{M}$ Aza-dC $+5 \mathrm{mM} \mathrm{NaB}(0.5 \mathrm{~A}+5 \mathrm{~N})$ and $5 \mu \mathrm{M}$ Aza-dC $+5 \mathrm{mM} \mathrm{NaB}(5 \mathrm{~A}+5 \mathrm{~N})$ for 2 days (A and B) and 6 days (C and D) were immunoprecipitated with acetyl-histone $\mathrm{H} 3$ (acH3), acetyl-histone $\mathrm{H} 4$ (acH4) and IgG antibodies. Inputs and 'NoAb' samples from each treatment were also included in the qPCR and used for calculations of enrichment over noise normalized to input (fold change to input, FC). qPCR was performed with wild-type primers specific for AR gene promoter region (93-bp DNA fragment). Asterisks show statistically significant differences between each treatment compared to control DMSO for appropriate antibody. ${ }^{p}<0.05$ value, ${ }^{* *} \mathrm{p}<0.0001$.

0.012 , respectively). The DU145 cell line showed significantly decreased histone $\mathrm{H} 4$ acetylation after all treatments except the control DMSO and $5 \mu \mathrm{M}$ Aza-dC applications that led to increased histone $\mathrm{H} 4$ acetylation. In normal RWPE-1 cells (Fig. 4C and D), the control DMSO, $5 \mu \mathrm{M} \mathrm{Aza-dC}$ and $0.5 \mu \mathrm{M}$ Aza-dC $+5 \mathrm{mM} \mathrm{NaB}$ treatment showed higher levels of histone $\mathrm{H} 3$ acetylation in comparison with shorter 2-day incubation ( $\mathrm{p}=0.036, \mathrm{p}=0.025$ and $\mathrm{p}=0.037$, respectively). We found no significant changes in histone $\mathrm{H} 3$ acetylation for the other treatments. For increasing histone $\mathrm{H} 4$ acetylation in normal prostate cells effective was the $0.5 \mu \mathrm{M}$ Aza-dC + $5 \mathrm{mM} \mathrm{NaB}$ combination. Other treatments were significantly less effective after 6-day exposure.

Cell cycle distribution explains the NaB induced cell death in prostate cancer cells. To determine the influence of Aza-dC and $\mathrm{NaB}$ on cell cycle regulation, exponentially growing RWPE-1 and DU145 cells were treated with the same treatment scheme as for RT-PCR and ChIP analysis. Cell cultures, including detached cells, were collected, stained with PI and DNA content was assessed by flow cytometry (Fig. 5).
By comparing the profiles of control (DMSO) and Aza-dC treated cell cultures after 2 days, the accumulation of cells in $\mathrm{S}$ and G2/M stages was shown moderately for RWPE-1 cells and more prominent in DU145 cells. Prolonged Aza-dC treatment (6 days) revealed obvious difference in effectiveness of G2/M arrest between compared cell lines. While significant and specific accumulation of RWPE- 1 cells in the G2/M compartment of the cell cycle was observed, the DU145 cells massively died, yielding predominant sub-G1 population reaching up to $80 \%$. The treatment with $5 \mathrm{mM} \mathrm{NaB}$ resulted in a much more conclusive contrast between normal and cancer cells. The RWPE-1 cells survived 2-day NaB treatment effectively, employing the G2/M arrest, while $79 \%$ of DU145 cells was shifted to sub-G1 compartment, indicating cell death. After 6 days of the NaB treatment, more than one half of RWPE-1 cells were cycling, at the same time $>90 \%$ of DU145 cells were dead, belonging to sub-G1 cell population.

Combination treatment at lowest concentration $(0.5 \mu \mathrm{M}$ Aza-dC $+1 \mathrm{mM} \mathrm{NaB}$ ) was more efficient than the Aza-dC treatment alone. G2/M accumulation was observed after 2-day treatment, with appearance of the sub-G1 cell population 
Treatment

RWPE-1

DU145

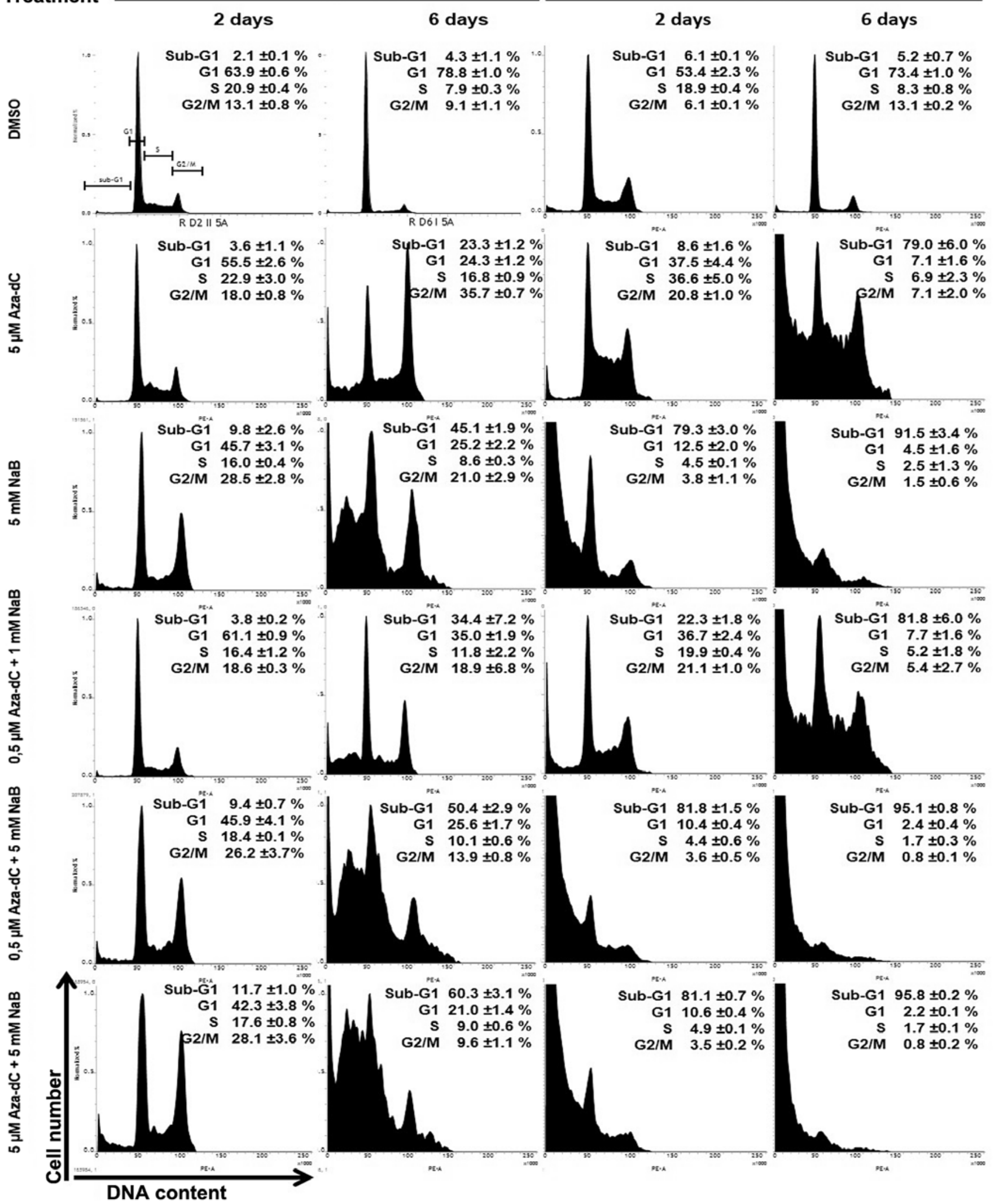

Figure 5. Effects of Aza-dC, NaB and their co-treatments on cell cycle distribution in human prostate cell lines, cancer DU145 and normal RWPE-1. Histogram plots of flow cytometry analysis of DNA content are representative. The numbers indicate the percentage of cells at the G0/G1 and G2/M stages, each value represents the mean of three independent experiments \pm SD.

specifically in DU145 cells. Prolonged 6-day treatment led to divergent response of both cell lines, revealing effective G2/M arrest for RWPE-1 cell line and high degree of cell death for DU145 exhibiting $<20 \%$ of cells in the cycle. Combination 
therapy with higher concentrations $(0.5 \mu \mathrm{M}$ Aza-dC $+5 \mathrm{mM}$ $\mathrm{NaB}$ and $5 \mu \mathrm{M}$ Aza-dC $+5 \mathrm{mM} \mathrm{NaB}$ ) resulted in generation of strong sub-G1 population in DU145, reaching $>80 \%$ within 2 days of treatment. More than $95 \%$ of DU145 cells were shown to be sub-G1 for both concentrations after 6 days, suggesting that at $0.5 \mu \mathrm{M}$ Aza-dC $+5 \mathrm{mM} \mathrm{NaB}$ combination treatment reached its plateau. Highest concentrations of combination treatment resulted in dose-dependent $\mathrm{G} 2 / \mathrm{M}$ accumulation of RWPE- 1 cells after 2 days, followed by appearance of sub-G1 cells after day 6 .

\section{Discussion}

Histone modification and DNA methylation are associated with transcriptional repression and integrally linked with following synergistic/additive effects (19). In our study we used two types of epigenetic agents: sodium butyrate, a naturally occurring HDAC inhibitor known for its selective cell toxicity, and 5'-Aza-2'-deoxycytidine, an inhibitor DNMT, and one of the most promising and extensively used demethylating agents. The aim of this study was to select optimal concentrations or combination of concentrations of these inhibitors to achieve an epigenetic effect leading to AR gene restoration in androgen-independent prostate cancer cells.

The cancer DU145 cell line is androgen-independent and characterized by strong DNA methylation of the AR gene $(17,20)$. This cell line is used as a model for simulating the conditions found in CRPC patients with changed genomic methylation patterns. We found that cancer line DU145 treated with the inhibitors used showed a substantial decrease in cell viability especially after $5 \mathrm{mM} \mathrm{NaB}$ administration and on 6-day exposure. $\mathrm{NaB}$ toxicity is a problem as to be effective as an inhibitor of histone deacetylases, $\mathrm{NaB}$ at the higher $5 \mathrm{mM}$ concentration is needed. Comparing the required levels of cytotoxicity for $\mathrm{NaB}$ alone and $\mathrm{NaB}+$ Aza-dC co-treatments ( 0.5 and $5 \mu \mathrm{M}$ Aza-dC with $5 \mathrm{mM} \mathrm{NaB}$ ), it is clear that adding of the Aza-dC could have the same or better anti-proliferative effect with lower cell toxicity than $5 \mathrm{mM} \mathrm{NaB}$ alone in DU145 cells. The shorter 2-day treatments with used inhibitors had little effect, except for the $\mathrm{NaB}$ treatment that showed slight cytotoxicity in DU145 cells, and on the other hand growth stimulation in RWPE-1 cells. Similar results were reported by Paskova et al (21), where $\mathrm{NaB}$ (in $0.5,1,2.5$ or $5 \mathrm{mM}$ concentrations) had no toxic effect on normal RWPE-1 cells after 2-day treatment.

In accordance with the cell viability assay, the cell cycle distribution results showed similar effects of the used treatments, namely massive cell death upon $5 \mathrm{mM} \mathrm{NaB}$ treatment (administered alone and in co-treatment with Aza-dC) in DU145 cells compared to RWPE-1 cells. The finding that $\mathrm{NaB}$ inhibits cell viability and proliferation in DU145 cells and in certain other prostate cancer cell lines, in a time- and dose-dependent manner has been described in several studies (22-25). Pro-apoptotic activity induced by high doses of Aza-dC $(\sim 5 \mu \mathrm{M})$ has also been reported (26). In our study, Aza-dC alone also induced cell death (79\% cells in sub-G1 cell population) in DU145 cells, however the co-treatments did not impair the toxic effects of $\mathrm{NaB}$ itself on the cell cycle. Although the cell death using a single inhibitor appears to be high, the combination of the two inhibitors might not have cumulative impact on prostate cancer cells. The appearance of the sub-G1 population of cells is apparently due to the DNA fragmentation of dead cells and could be a result of the proapoptotic $\mathrm{NaB}$ activity in cancer DU145 cells $(24,25)$. A strong contrast of cell cycle distribution between both cell lines is given also by features of p-53 proficient RWPE- 1 and p-53 deficient DU145 cells leading to p53-dependent activation and maintenance of $\mathrm{G} 2 / \mathrm{M}$ cell cycle arrest and better survival in RWPE-1 cells compared to DU145 cells.

DU145 cells contain a methylated AR gene, thus the cell line has very low or undetectable AR gene expression (no $\mathrm{Ct}$ value in control DMSO treatment after 50 cycles was detected). The $\mathrm{Ct}$ value was established arbitrarily as $\mathrm{Ct} 50$ at both time-points. Hence, the real re-expression of the AR gene could be considered higher than that calculated here for DU145 cells. In DU145, the most effective AR mRNA restoration was treatment with $0.5 \mu \mathrm{M}$ Aza-dC $+5 \mathrm{mM} \mathrm{NaB}$ for both time-points, while the RWPE-1 cells did not show the same pattern and no significant difference between individual treatments was found after day 6 . Although we noted an increased AR gene expression in RWPE-1, the level of mRNA was low compared to AR expression in DU145 cells. We observed a tendency to a decline in AR gene expression in a time-dependent manner apparent for both cancer and normal cell lines. The declining trend was also shown in histone $\mathrm{H} 4$ acetylation of the AR gene. As we changed the medium after 2 days, the half-life of inhibitors and recovery of remodulation enzymes, HDAC I and IIa that are targets of $\mathrm{NaB}$ (27), could result in lower AR gene re-expression and especially lower histone $\mathrm{H} 4$ acetylation.

We found significant re-acetylation of the histone $\mathrm{H} 4$ compared to control DMSO in cancer DU145 cells treated with the $0.5 \mu \mathrm{M}$ Aza- $\mathrm{dC}+1 \mathrm{mM} \mathrm{NaB}$ combination, while the same treatment induced significantly lower $\mathrm{H} 4$ acetylation levels in normal RWPE-1 cells. On the other hand, $0.5 \mu \mathrm{M}$ Aza-dC + $5 \mathrm{mM} \mathrm{NaB}$ co-treatment had the same effect on both cell lines by increased enrichment of histone $\mathrm{H} 4$ acetylation while the $5 \mu \mathrm{M}$ Aza-dC $+5 \mathrm{mM} \mathrm{NaB}$ had only moderate effect. This implies that low $\mu \mathrm{M}$-concentration of Aza-dC together with $\mathrm{mM}$-concentration of $\mathrm{NaB}$ could have either an additive/synergistic or antagonistic effect on chromatin remodeling.

The CRPC stadium harbours heterogeneous features present with multiple alterations in the AR gene function. Besides mutations, copy number changes, deregulation of coregulators, and splice variants in AR gene, DNA methylation appears to be a minor modification contributing to AR gene dysfunction. However, based on a relatively recent study (12), the AR gene promoter methylation is likely related to prostate stem/progenitor traits and linked to enhanced castration resistance. Prostate tumor consists of a mixture of normal/benign, cancer and cancer stem cells with aberrant methylation profile. It is noteworthy that AR gene re-expression using epigenetic therapy leads to decreased proliferation and longer survival (13-15). AR signaling does not aggravate the development of the disease. It may act as a physiological regulator of AR downstream genes and sensitizes the cancer cells to other phases of therapy. For this reason, research efforts might be focused on keeping the active AR gene at low expression level to preserve the native AR signaling axis and to determine whether the restored AR gene could have regulation capability. Although 
we showed a markedly increased AR mRNA expression and significant re-acetylation of histone $\mathrm{H} 4$ around AR gene promoter upon the co-treatment in DU145 cells, we assume that the corresponding AR gene regulation was not restored as the PSA level was not detected. Moreover, the high frequency of sub-G1 population of the dead cells was observed. To promote growth in androgen-independent $\mathrm{CaP}$, the active AR should have selective and direct upregulation effect on M-phase cell cycle genes (28). Therefore, the cell cycle distribution results appear to be solely a consequence of $\mathrm{NaB}$ and Aza effects on cell death genes $(24,25)$ and not by activation/restoration of AR. Modulation of the AR activity is mediated by the action of numerous coactivators and corepressors [histone modifiers, splice proteins, proteins of RNA metabolism and DNA repair, and cell cycle regulators (29)] and by phosphorylation of both AR and the mentioned co-regulators (30). It indicates further analysis is required aimed at mechanisms of action of epigenetic inhibitors and their potential role leading to completely active AR.

In conclusion, the impact of the combined treatment shows cancer cell reduction of their proliferative activity and changes in cell cycle distribution in comparison with normal cells with time-dependent effect. Further, the combined treatment both strongly increased histone $\mathrm{H} 4$ acetylation in the AR gene promoter and induced the AR gene re-expression in cancer cells in comparison with the normal cell line. Our results imply selective toxicity of used inhibitors with a suggestion that appropriately chosen inhibitor combination and concentration may have synergism/additive potential for therapeutic procedures in CRPC patients.

\section{Acknowledgements}

The authors would like to thank Jana Holinková, Eva Pimrová, Lenka Prokopová, Jana Fialová Kučerová and Kateřina Č́žková for technical assistance. Alexander Oulton is acknowledged for critical reading of the manuscript. This study was supported by grants IGA_LF_2016_013, PU I LO1304 and RVO: 61989592 from the Czech Ministry of Education and The Kellner Family Foundation.

\section{References}

1. Han G, Foster BA, Mistry S, Buchanan G, Harris JM, Tilley WD and Greenberg NM: Hormone status selects for spontaneous somatic androgen receptor variants that demonstrate specific ligand and cofactor dependent activities in autochthonous prostate cancer. J Biol Chem 276: 11204-11213, 2001.

2. Steinkamp MP, O'Mahony OA, Brogley M, Rehman H, Lapensee EW, Dhanasekaran S, Hofer MD, Kuefer R, Chinnaiyan A, Rubin MA, et al: Treatment-dependent androgen receptor mutations in prostate cancer exploit multiple mechanisms to evade therapy. Cancer Res 69: 4434-4442, 2009.

3. Li P, Yang R and Gao W-Q: Contributions of epithelial-mesenchymal transition and cancer stem cells to the development of castration resistance of prostate cancer. Mol Cancer 13: 55, 2014.

4. Friedlander TW, Roy R, Tomlins SA, Ngo VT, Kobayashi Y, Azameera A, Rubin MA, Pienta KJ, Chinnaiyan A, Ittmann $\mathrm{MM}$, et al: Common structural and epigenetic changes in the genome of castration-resistant prostate cancer. Cancer Res 72: 616-625, 2012.

5. Berrevoets CA, Veldscholte $\mathrm{J}$ and Mulder E: Effects of antiandrogens on transformation and transcription activation of wild-type and mutated (LNCaP) androgen receptors. J Steroid Biochem Mol Biol 46: 731-736, 1993.
6. McDonald S, Brive L, Agus DB, Scher HI and Ely KR: Ligand responsiveness in human prostate cancer: Structural analysis of mutant androgen receptors from LNCaP and CWR22 tumors. Cancer Res 60: 2317-2322, 2000.

7. Felgueiras J, Silva JV and Fardilha M: Prostate cancer: The need for biomarkers and new therapeutic targets. J Zhejiang Univ Sci B 15: 16-42, 2014.

8. Schrecengost R and Knudsen KE: Molecular pathogenesis and progression of prostate cancer. Semin Oncol 40: 244-258, 2013.

9. Nelson WG, Yegnasubramanian S, Agoston AT, Bastian PJ, Lee BH, Nakayama $M$ and De Marzo AM: Abnormal DNA methylation, epigenetics, and prostate cancer. Front Biosci 12: 4254-4266, 2007.

10. Yegnasubramanian S, Haffner MC, Zhang Y, Gurel B, Cornish TC, Wu Z, Irizarry RA, Morgan J, Hicks J, DeWeese TL, et al: DNA hypomethylation arises later in prostate cancer progression than $\mathrm{CpG}$ island hypermethylation and contributes to metastatic tumor heterogeneity. Cancer Res 68: 8954-8967, 2008.

11. Scher HI and Sawyers CL: Biology of progressive, castrationresistant prostate cancer: Directed therapies targeting the androgen-receptor signaling axis. J Clin Oncol 23: 8253-8261, 2005.

12. Tian J, Lee SO, Liang L, Luo J, Huang CK, Li L, Niu Y and Chang $\mathrm{C}$ : Targeting the unique methylation pattern of androgen receptor (AR) promoter in prostate stem/progenitor cells with 5-aza-2'-deoxycytidine (5-AZA) leads to suppressed prostate tumorigenesis. J Biol Chem 287: 39954-39966, 2012.

13. McCabe MT, Low JA, Daignault S, Imperiale MJ, Wojno KJ and Day ML: Inhibition of DNA methyltransferase activity prevents tumorigenesis in a mouse model of prostate cancer. Cancer Res 66: 385-392, 2006.

14. Zorn CS, Wojno KJ, McCabe MT, Kuefer R, Gschwend JE and Day ML: 5-aza-2'-deoxycytidine delays androgen-independent disease and improves survival in the transgenic adenocarcinoma of the mouse prostate mouse model of prostate cancer. Clin Cancer Res 13: 2136-2143, 2007.

15. Gravina GL, Marampon F, Di Staso M, Bonfili P, Vitturini A, Jannini EA, Pestell RG, Tombolini V and Festuccia C: 5-Azacitidine restores and amplifies the bicalutamide response on preclinical models of androgen receptor expressing or deficient prostate tumors. Prostate 70: 1166-1178, 2010.

16. Gao L and Alumkal J: Epigenetic regulation of androgen receptor signaling in prostate cancer. Epigenetics 5: 100-104, 2010.

17. Fialova B, Smesny Trtkova K, Paskova L, Langova K and Kolar Z: Effect of histone deacetylase and DNA methyltransferase inhibitors on the expression of the androgen receptor gene in androgen-independent prostate cancer cell lines. Oncol Rep 29: 2039-2045, 2013.

18. Trtkova K, Paskova L, Matijescukova N, Strnad M and Kolar Z: Binding of AR to SMRT/N-CoR complex and its co-operation with PSA promoter in prostate cancer cells treated with natural histone deacetylase inhibitor NaB. Neoplasma 57: 406-414, 2010.

19. Walton TJ, Li G, Seth R, McArdle SE, Bishop MC and Rees RC: DNA demethylation and histone deacetylation inhibition co-operate to re-express estrogen receptor beta and induce apoptosis in prostate cancer cell-lines. Prostate 68: 210-222, 2008.

20. Jarrard DF, Kinoshita H, Shi Y, Sandefur C, Hoff D, Meisner LF, Chang C, Herman JG, Isaacs WB and Nassif N: Methylation of the androgen receptor promoter $\mathrm{CpG}$ island is associated with loss of androgen receptor expression in prostate cancer cells. Cancer Res 58: 5310-5314, 1998

21. Paskova L, Smesny Trtkova K, Fialova B, Benedikova A, Langova K and Kolar Z: Different effect of sodium butyrate on cancer and normal prostate cells. Toxicol In Vitro 27: 1489-1495, 2013.

22. Kim J, Park H, Im JY, Choi WS and Kim HS: Sodium butyrate regulates androgen receptor expression and cell cycle arrest in human prostate cancer cells. Anticancer Res 27A: 3285-3292, 2007.

23. Pajak B, Orzechowski A and Gajkowska B: Molecular basis of sodium butyrate-dependent proapoptotic activity in cancer cells. Adv Med Sci 52: 83-88, 2007.

24. Qiu J, Gao Z and Shima H: Growth of human prostate cancer cells is significantly suppressed in vitro with sodium butyrate through apoptosis. Oncol Rep 27: 160-167, 2012. 
25. Mu D, Gao Z, Guo H, Zhou G and Sun B: Sodium butyrate induces growth inhibition and apoptosis in human prostate cancer DU145 cells by up-regulation of the expression of Annexin A1. PLoS One 8: e74922, 2013.

26. Patra A, Deb M, Dahiya R and Patra SK: 5-Aza-2'-deoxycytidine stress response and apoptosis in prostate cancer. Clin Epigenetics 2: 339-348, 2011.

27. Zhang $\mathrm{J}$ and Zhong Q: Histone deacetylase inhibitors and cell death. Cell Mol Life Sci 71: 3885-3901, 2014.
28. Wang Q, Li W, Zhang Y, Yuan X, Xu K, Yu J, Chen Z, Beroukhim R, Wang $\mathrm{H}$, Lupien $\mathrm{M}$, et al: Androgen receptor regulates a distinct transcription program in androgen-independent prostate cancer. Cell 138: 245-256, 2009.

29. Heemers HV and Tindall DJ: Androgen receptor (AR) coregulators: A diversity of functions converging on and regulating the AR transcriptional complex. Endocr Rev 28: 778-808, 2007.

30. Heinlein CA and Chang C: Androgen receptor in prostate cancer. Endocr Rev 25: 276-308, 2004. 